This is an Accepted Manuscript of an article published by Taylor \& Francis Group in Oxford Review of Education on 10/01/2014, available online:

http://www.tandfonline.com/doi/pdf/10.1080/03054985.2013.873524

Published as:

Boyden, Jo and Zoe James (2014) 'Schooling, childhood poverty and international development: choices and challenges in a longitudinal study', Oxford Review of Education 40 (1): 10-29. DOI: $10.1080 / 03054985.2013 .873524$

This article is reproduced in accordance with the self-archiving policies of Taylor \& Francis. 


\title{
Schooling, Childhood Poverty and International Development: choices and challenges in a longitudinal study
}

\author{
Jo Boyden ${ }^{\mathrm{a}}$ and Zoe James ${ }^{\mathrm{b}}$ \\ a Corresponding author: Young Lives, University of Oxford, Department of International Development, \\ 3, Mansfield Road, OX1 3TB. jo.boyden@geh.ox.ac.uk \\ b Young Lives, University of Oxford, Department of International Development, 3 Mansfield Road, \\ OX1 3TB.
}

\section{Notes on contributors}

Jo Boyden is Director of Young Lives, University of Oxford, UK

Zoe James is a Researcher at Young Lives, University of Oxford, UK and a doctoral student at the Institute of Education, University of London, UK.

\section{Acknowledgements}

The authors would like to thank John Bynner, Gina Crivello, Sofya Krutikova, Angela Little, Virginia Morrow, Caine Rolleston, Martin Woodhead, and two anonymous reviewers for their comments on earlier drafts.

\section{$\underline{\text { Abstract }}$}

Due to the rarity of longitudinal data, evidence on the benefits of education across the life-course is relatively sparse in developing countries. Young Lives is the only comparative dual-cohort study to combine data collection using mixed-methods at child, household, school and community levels, following 12,000 children in two cohorts across four countries since 2002. This article outlines the conceptual and analytical framework and the key methodological features of the Young Lives study, and the unique potential of the data for analysis of educational trajectories, and of the influences that shape them. It discusses the challenges associated with a crosscountry interdisciplinary study of children, their families and schools; including epistemological, logistical and ethical challenges; and examines how these were addressed. These include logistical, epistemological and ethical challenges of ensuring the integrity of the panel data and cohort, maintaining an appropriate degree of consistency across countries in terms of design and measurement, without compromising policy relevance at the national level, and balancing the sometimes competing demands for cross-sectional and longitudinal evidence. 


\section{Introduction}

Longitudinal studies have a respected place in educational and social research, but are still relatively rare in developing countries. Young Lives multi-dimensional and longitudinal research design collects parallel data across four low- and middle-income countries, Ethiopia, India (in the state of Andhra Pradesh), Peru and Vietnam. ${ }^{1}$ As a panel study of a dual birth cohort in each of these countries, Young Lives provides unique potential for analyses of educational trajectories in impoverished contexts and of the influences that shape them. Now in its fourth phase of operation (2009-17), Young Lives was founded at the beginning of the $21^{\text {st }}$ Century to inform policies and programmes to reduce child poverty through research and policy engagement. The study is following 12,000 children, their caregivers, and selected community representatives over 15 years, starting in 2002. In 2007 the design was extended to include qualitative research with a sub-sample of the children and their peers and in 2010 a further addition entailed surveys of schools attended by Young Lives children and their peers.' The initial sample of children comprises two age cohorts: 2,000 children in each country who were born in 2001-02 (the younger cohort) and roughly 1,000 children born in 1994-95 (the older cohort).

This article begins by briefly outlining the educational context for Young Lives before moving on to describe the conceptual and analytical framework of the study and its key methodological features. It then discusses the major challenges associated with a cross-country interdisciplinary study of children, their families, communities and schools and examines how these have been addressed. These include logistical, epistemological and ethical challenges of ensuring the integrity of the panel data and cohort, maintaining an appropriate degree of consistency across countries in terms of design and measurement, without compromising policy relevance at the national level, and balancing the sometimes competing demands for cross-sectional and longitudinal evidence.

\section{Context for Young Lives Research}

In recent decades, formal education has emerged as among the most significant features of children's lives throughout the developing world. Dramatic expansion of education systems over the past few decades has been accompanied by an international push for universal access, via Education for All (EFA) and the Millennium Development Goals (MDGs), such that primary school participation stands at near universal level in many countries, including those involved in Young Lives. Expectations and experiences of schooling are a key reference point for children's well-being and development, with raised educational aspirations linked strongly to ambitions for future livelihoods. Educational advancement also appears centre-stage among potential policy-levers for poverty-reduction and national economic growth. Nevertheless, while significant progress has been made on enrolment and access

\footnotetext{
${ }^{1}$ The study countries were selected to include one from each of the major regions of the developing world, along with a range of political-economic conditions and circumstances, with strong institutional capacity locally to undertake complex panel research being another crucial criterion.
} 
globally, it is clear that key education goals (related to both the MDGs and EFA) are still not on track. Although the power of the MDGs as an international call to action is widely acknowledged, the emphasis on enrolment has not created adequate incentives to engage with quality imperatives (UNESCO, 2005) or relevance; nor has basic equity in enrolment and retention been achieved, in far too many cases. With this in mind, the focus of many educationalists is shifting toward what is learned in school, and the imperative of "Learning for All" seems set to shape the post-2015 agenda (Brookings, 2011; DFID, 2010).

Questions about access, quality and relevance have been central to recent policy research programmes, notably, the DFID-funded Education Research Consortia (CREATE, ${ }^{2} \mathrm{EdQual}^{3}$ and RECOUP ${ }^{4}$ ). However it is increasingly accepted that none of these dimensions can be studied - or reformed - in isolation from the others. Recognising the multiple influences on school enrolment, learning and teaching quality and skills development has led to calls for a reassertion of a more holistic EFA agenda (Lewin, 2007). School effectiveness research takes account of influences on learning at national, community, school and classroom levels, to understand the role of inputs into educational processes. However, the international literature is somewhat inconclusive concerning the importance of precise inputs (Glewwe et al, 2011) and research in this area is particularly scant in developing-country contexts.

In terms of measuring educational achievement, several international testing programmes are well-established, including PIRLS (on reading), TIMSS (on math and science achievement), ${ }^{5}$ and PISA (on reading comprehension, math and scientific literacy). ${ }^{6} \mathrm{~A}$ few developing countries have participated in these studies and there have been regional attempts to measure achievement in Africa (PASEC and SACMEQ) ${ }^{7}$ and Latin America (LLECE). ${ }^{8}$ There are some common messages arising from these evaluations, such as: 1 ) while school enrolment is increasing (especially at the primary level), the majority of children in developing countries do not achieve at educational levels that would be expected given their age and grade; 2) achievement is closely tied to household characteristics, such as parental education, income, area (with poorer results for rural students), maternal language (with poorer results for children from ethnic minorities) and in many cases gender (e.g. lower scores for girls in math). However, much of the international literature and many of these studies are

\footnotetext{
${ }^{2}$ Consortium for Research on Educational Access, Transitions and Equity (http://www.create-rpc.org).

${ }^{3}$ Research Consortium on Educational Outcomes and Poverty (RECOUP) (http://recoup.educ.cam.ac.uk).

${ }^{4}$ Research Programme Consortium on Implementing Education Quality in Low Income Countries (http://www.edqual.org).

${ }^{5}$ TIMSS is the Trends in International Mathematics and Science Study and PIRLS is the Progress in International Reading Literacy Study (http://www.iea.nl/).

${ }^{6}$ The Programme for International Student Assessment (PISA)

7 'The Program on the Analysis of Education Systems' includes 13 francophone countries (http://www.confemen.org/le-pasec/) and The Southern and Eastern Africa Consortium for Monitoring Educational Quality includes 15 countries, but not Ethiopia (http://www.sacmeq.org/).

8 The Latin American Laboratory for Assessment of the Quality of Education, in which Peru has participated (http://portal.unesco.org).
} 
cross-sectional, thereby limiting their potential for the identification of causal pathways. Evidence-based policy making therefore stands to benefit from the possibilities offered by longitudinal, multi-level research which links schooling to wider poverty reduction agendas.

\section{Section 2 Young Lives conceptualisation and research design}

\section{Conceptual and analytical framework}

The epistemological basis for Young Lives draws on diverse disciplinary perspectives, including economics, anthropology and psychology, reflected in the range of analytical procedures, broad conceptual framework and methods employed in the research. On the understanding that no single measure, not even a multivariate index, could effectively represent the many facets of poverty, the study envisions this core concept in multidimensional terms (Dercon, 2011). The main criteria used to classify poverty levels among Young Lives households are consumption, expenditure and assets, together with exposure to economic and other shocks, livelihood stability, social connectedness and infrastructure and service access. Similarly, Young Lives employs broad conceptions of child wellbeing and child development that encompass diverse developmental domains-physical, social, psychological, cognitive, etc-and a mix of objective and subjective indicators. Survey research is complemented by qualitative in-depth studies of a sub-sample of children focussing on topics such as their responsibilities and time use, friendships, sources of learning and support, and their perceptions of and aspirations for schooling. The resultant Young Lives data sets permit analysis across a very wide range of themes, of which education is just one, but an increasingly important strand of the current research programme.

Overall, the research is guided by three intersecting lines of enquiry, each of which has an important bearing on childhood poverty, and the role of formal school education. The first involves life-course analysis of the factors shaping children's growth and development. It examines what matters most for which children at which age points, the (different) effects of risk and resilience factors for children at different ages, and how far influences in early childhood are critical for long-term outcomes (e.g. Dearden et al., 2013; Outes-Leon \& Porter, 2013). The second works from the understanding that risk and deprivation are concentrated in particular social groups and localities, with dramatic disparities in children's outcomes, and questions what these inequalities mean for children. By including roughly equal numbers of boys and girls in the sample, and by covering rural and urban populations, as well as groups distinguished by ethnicity, caste, religion and language, it shows how differences in geographic location and social status affect children's life chances over time (e.g. Dercon and Singh, 2013; Woodhead et al, 2013a; Woodhead, et al 2013b).

The third line of enquiry examines the changing influences in children's lives, including the risks they are exposed to and support they enjoy; specifically via cohort comparisons; and more generally by linking household and child data to the politicaleconomic, socio-cultural and institutional context, notably the growth of schooling. 
There has been major investment in formal education in the four countries since the study began and this is associated with high levels of enrolment among Young Lives children. Thus, in 2002, primary school enrolment was already near-universal across Young Lives children in India, Peru and Vietnam, at 97 per cent or above, and had grown very rapidly between the two cohorts in Ethiopia to 77 per cent of 8-year olds in 2009 (Murray, 2012). In all four countries, expanded educational opportunities are linked with raised educational aspirations and significant changes in children's time use, although not necessarily with improvements in education quality or equity in access or learning outcomes (Rolleston et al 2013a;).

\section{Study Design and Methodology}

\section{Rationale for longitudinal research}

There is considerable complexity in the Young Lives methodology and design (see also Barnett et al 2012). The basis for the evolving design was the selection of appropriate methods to enable assessment of epistemologically-diverse dimensions of child poverty. The conceptual framework allows key research questions to be addressed about the consequences of poverty and impacts of school, but also encourages questioning of received wisdom, not least by engaging with children's own understandings of their lives. A further feature of Young Lives is the provision of credible evidence for policy on how changing social and economic circumstances, disadvantages and shocks, in diverse contexts, affect different groups of children over time. These goals are well addressed through a cross-country, longitudinal, cohort study.

Longitudinal research has many advantages over other designs since it enables examination of poverty duration and dynamics, causal relations and pathways across multiple levels and units of observation, as well as children's experiences and outcomes as they persist and/or vary over time. Bynner and Joshi $(2007 ; 2)$ highlight the investigative strengths of this approach as encompassing both prospective data analysis which allows 'predictions about the outcomes of particular circumstances and experiences in life' and retrospective analysis which identifies 'the experiences and circumstances in earlier life that lie behind a given outcome observed later'. Five core elements can be identified as key to the study's conceptualisation of poverty and child development: mixed-methods research; a prospective design with longitudinal followups; extensive multi-dimensional data on children's development, wellbeing and perspectives; child, household, community and school information that permits investigation of causal pathways and interrelations; and the use of a common core of instruments and research methods across the four countries (involving translation and adaptation into at least twelve languages). Use of common instruments ensures simplicity of administration and, where appropriate, enables a cross-country perspective on the interactions and pathways involved in particular key topics that emerge across the study contexts. 


\section{Why a dual cohort}

Initially, the intention was to follow a single cohort of 8,000 children born at the start of the Millennium - the younger cohort. The older cohort of children was included as a means of testing the suitability of instruments and questions for administration with the younger children when they reached the same age. However, in time, it became clear that there was much to be gained by retaining the older cohort in the study for this would permit both inter-cohort analysis and research on the transition into adulthood. Consequently, both cohorts are now central to the study design. The inclusion of two comparable cohorts in Young Lives offers the opportunity to trace pathways and dynamics for individual children in different phases of the life cycle and to compare the situation of children of the same age at different points in time, enabling examination of the impacts of rapidly changing country contexts and the separation of cohort and period effects (Bynner, 2005). The younger cohort of children has been researched since infancy, tracing the ways that early deprivations and shocks shape life-course trajectories, and analysing which factors modify the impacts. The older cohort, first surveyed at age 8 , has now reached adolescence, a life-phase of critical interest to social planners who are concerned to understand how educational experiences and outcomes shape livelihoods and other aspects of adult life. Additional data on selected younger siblings permit an understanding of intra-household dynamics (e.g. Porter et al, 2012).

\section{Sentinel site methodology}

The sample is designed broadly in line with sentinel site surveillance methodology and is concentrated in 80 purposively selected sites across the four countries (Wilson et al, 2006). This methodology is more commonly used in health surveillance surveys, but offers numerous advantages to a study like Young Lives. Above all, whilst national representativeness may be desirable, it is often unattainable in developing country contexts where population data may be incomplete, inaccessibility and instability may limit where it is possible to work or increase costs to unrealistic levels, and where government may place restrictions on access. The Young Lives sites were selected non-randomly from the poorer regions in each country so as to also illustrate the social diversity of the national population, capturing the widest possible heterogeneity to the same extent within each country. Within each sentinel site households with a child of the correct age were identified and 150 were randomly selected, although procedures sometimes varied between sites because of 'topographical and administrative differences within and between countries' (Barnett et al, 2012: 2). Such an approach is well suited to analysis of relationships and their interactions across varied contexts, including the analysis of causal relationships, but is not appropriate for reporting of cross-sectional national-level descriptive results, or conducting standard crosscountry analyses (Wilson et al 2006).

\section{<INSERT FIGURE 1 HERE>}

Household-level survey 
The household-level survey research comprises five data rounds conducted at approximately 3-year intervals across the full sample of children and caregivers, and with selected siblings and community representatives. It combines child, caregiver and community questionnaires with several measures to gauge children's development. Survey questionnaires have been designed to yield data that can easily be compared both between the four countries and over time. The caregiver questionnaire focuses on explanatory variables at the caregiver level, for example their level of education and involvement in and aspirations for children's education, as well as variables at the household level, such as assets and livelihoods (as indicated above). Country-specific modules investigate governmental policies and programmes, budgets, and actual spending on services such as health and education at the community level. Community questionnaires are administered in all communities in Young Lives sentinel sites and a shorter version is administered in new sites to which children have migrated. These instruments address community resources and services, prices, economic shocks and also provide a list of schools.

The topics of the child questionnaires vary with age. However, they broadly cover school history, physical growth, nutritional status, subjective well-being, psychosocial wellbeing and time use and are supplemented by a series of child outcome measures that have been adapted from other studies to be suitable for the Young Lives country contexts. Anthropometric measurements are obtained through height-for-age, weight-for-age and BMI-for-age measures. Receptive vocabulary is arrived at through the Peabody Picture Vocabulary Test and quantitative understanding through the Cognitive Development Assessment, providing proxies for cognition. Academic achievement is measured variously between cohorts and rounds through instruments including the Early Grade Reading Assessment, and numeracy and mathematics assessments which draw on international test batteries.

\section{$<$ INSERT TABLE 1 HERE>}

\section{Qualitative research}

The surveys are complemented by four rounds of more in-depth qualitative research conducted at household level with a sub-sample of approximately 50 children in each country ( 25 from each cohort), their caregivers and peers. The qualitative research is administered in three to five sites in each country, chosen to capture variations in location (rural/urban and regional), ethnicity (minority and majority groups), and social and economic circumstances, based on Round 2 survey community-level variables and through discussion with the survey teams. In 2007, 12 children (an equal number of boys and girls from both age cohorts) were purposively sampled from each of these sites. The children were selected randomly except in India (where we wanted to compare children with and without pre-school experience) and Ethiopia (where the Survey indicated high levels of parental death, so it was important to capture this within the qualitative sub-sample) (Crivello et al, 2013). 
The qualitative methods comprise semi-structured interviews and focus groups, drawing (such as community mapping and life-course 'draw-and-tell'), writing (a daily activity diary) and photo elicitation. Focusing on children's everyday experiences in poverty, it generates detailed narrative accounts from children and caregivers covering a range of topics, including boys' and girls' changing roles and responsibilities in households and communities, choices and decision-making, experiences of schooling and work, and their perspectives on what has contributed to shaping their situations and well-being, their aspirations and goals, and their expectations for future outcomes.

\section{Nested school surveys}

Although initially conceived of as a cohort study based primarily on child, household and community data, a series of nested school surveys were introduced in 2010 . This followed evidence from the first data rounds that formal schooling has assumed a major role in shaping children's lives, the second most important institutional setting for Young Lives children after the household. The information about schools, teachers, classes and peers that can be collected at the household level is limited, and while a cohort sample is well suited to topics such as educational aspirations and school enrolment, a more balanced sample at the school level is necessary to consider questions relating to, for example, school and teacher quality and effectiveness. These nested surveys were introduced when most younger-cohort children were already attending the early grades of school. As such, this component makes it possible to monitor school access and quality over time and to relate educational trajectories to outcomes as well as to children's and parents' aspirations and experiences, revealing how these various factors affect children in different locations and socio-economic groups through the life-course.

Nested school surveys have now taken place in Ethiopia in 2009 and 2012-13, in Andhra Pradesh in 2010-11, and in Peru and Vietnam in 2011-12. In all cases, the focus has been on including the younger cohort children and their peers. The design of these surveys has varied across countries, relating closely to concerns in education policy in each study setting and with instrument design informed by consultation with government and civil society actors working in education at the national and local levels. Sampling procedures have also varied and are briefly detailed in Table 2, but broadly speaking, each survey has visited either the schools attended by a sample of Young Lives children, or a sample of the schools located within the geographical boundaries of the sentinel site.

In all cases the school surveys have collected data at the school, principal, class, teacher and pupil level in relation to a specified grade(s), usually that in which the majority of the Young Lives younger cohort are enrolled. In Ethiopia (2012-13), Peru (2011) and Vietnam (2011-12) this has also involved non-Young Lives children studying in the class and in Ethiopia and Vietnam, visits at both the start and end of the school year, to enable a more robust examination of the role of school, class and teacher-level factors in mitigating household-level disadvantage. At the pupil level, 
background information has been collected together with tests of cognition and psychosocial competencies designed to assess learning in relation to curricular and grade-specific expectations. In Vietnam and Ethiopia (2012-13), a 'test and retest' design was also employed, with the survey being conducted at the beginning and end of the school year. As well as offering the opportunity of linking to the wider child and household panel (as in the single wave surveys), this facilitates standalone longitudinal school-effectiveness studies.

A selection of the school surveys (Ethiopia 2009; Andhra Pradesh 2010-11; Peru 2011-12) have included qualitative sub-studies focussed on particular research questions, often identified through the quantitative analysis. These have tended to involve a small, purposively selected, sub-sample of Young Lives children and their caregivers, as well as community members, school principals and teachers. For example, in Andhra Pradesh, a sub-study examining the reasons behind frequent school changes was undertaken with children and their caregivers in three purposively selected communities (see James \& Woodhead, this issue)).

\section{$<$ INSERT TABLE 2 HERE>}

\section{Ethics}

In developing ethical protocols, the study followed procedures laid out by the University of Oxford's Department of International Development, which were in turn adapted from the guidelines of the Association of Social Anthropologists of the Commonwealth (see Morrow, 2009 for a description of the ethical principles and practice observed in Young Lives). Ethical approval has been obtained from diverse bodies, including Oxford's Social Science Division Ethics Committee, and studycountry ethics committees, where they exist. The study follows the Save the Children UK Child Protection Policy in all of its interactions with children (Save the Children, 2003).

\section{Section 3: Methodological challenges}

This section outlines a selection of the most significant methodological challenges Young Lives has confronted since its inception, together with the strategies used to address them.

\section{Sample selection}

In household and child-level research in developing countries sample selection can be very complex, due to cost, geographical or infrastructural constraints, high population mobility, political factors, and absent or partial population data. Given these constraints, sentinel site methodology with a restricted number of purposively selected clusters (or sentinel sites) was considered the best way to capture a heterogeneous 
population sample to the same extent in each country. At the site level, the random selection of respondents enables analysis to focus on the measurement of change and the identification of causal effects. Arriving at a random sample of an appropriate number of boys and girls in the correct age groups was an exhaustive process. Households containing children of the appropriate ages were sampled randomly within the clusters, there being roughly equal numbers of boys and girls overall. In Peru alone, this meant interviewing 36,153 households over 280 days, since population data were not otherwise available ${ }^{9}$.

This sample frame reflects the major goals of the study - to investigate the impacts of child poverty on human development across four diverse countries - rather than offering monitoring evidence on the extent of child poverty per se. With child poverty the focus, site selection over represents poorer regions and populations, and includes diverse social groups, distinguished by religion, ethnicity, language and caste across both urban and rural areas. Comparisons of the Young Lives' samples to nationally representative samples ${ }^{10}$ reveal varied but not significantly diverging trends. In Ethiopia (Outes-Leon \& Sanchez, 2008), India (Kumra, 2008) and Peru (Escobal \& Flores, 2008) it was found that Young Lives households were slightly better-off and had better access to services than average households in the country, but that the sample did cover the broad diversity of children nationally in each case. In Vietnam (Nguyen, 2008), sample households were found to be poorer than those in nationallyrepresentative datasets, but sample children were similarly shown to represent the diversity of children across Vietnam well.

\section{Integrity of the cohorts}

\section{Attrition}

Maintaining the integrity of the sample is one of the most demanding and difficult requirements of any longitudinal study. Attrition is a significant concern as it inevitably accumulates over time, reducing sample size and, when not random, potentially leads to biased inferences; as such, attrition has been widely discussed in the survey literature (e.g. Alderman et al, 2000; Hill, 2004). Attrition may be due to diverse factors, most often respondent fatigue or changes in respondents' circumstances, especially migration. The main concern here is to keep in touch with and follow migrants and to conserve respectful relations with survey respondents; this latter requirement being central not only to cohort maintenance, but also to ethics and data quality.

Outes-Leon and Dercon (2008) report on the incidence of and potential bias arising from attrition in Young Lives following the completion of the second round of data

\footnotetext{
${ }^{9}$ Although in relation to the experiences of the other study countries this was the exception rather than the rule, since the clusters in Peru were more dispersed.

${ }^{10}$ In Ethiopia, comparison was made to the 2000 Demographic and Health Survey (DHS) and the 2000 Welfare Monitoring Survey (WMS); in India to the 1998/99 DHS; in Peru to the 2001 Living Standard Measurement Survey (LSMS) and the 2000 DHS; and in Vietnam to the 2001 Vietnam Household Living Standard Survey (VLSS) and the 2002 DHS.
} 
collection at household level. As it happens, consistent with other research in developing countries, the rate of attrition in the study is exceptionally low, at less than $0.5 \%$ p.a., with migration being one of the major causes where it does occur. The low rate is largely attributable to the close attention paid by country teams to tracking between data rounds and to building and maintaining good relations with respondents, local communities and local officials. Tracking is in itself a major operation, not least because few respondents have formal addresses, children sometimes migrate separately from adult household members and on occasion families move without informing others where they are going.

\section{<INSERT TABLE 3 HERE>}

\section{Respondent relations and ethics}

Cohort maintenance is also influenced by the degree to which respondents perceive the research to be burdensome or invasive; this depends on multiple factors, principally the application of high ethical standards, as reflected in the skill of field supervisors and enumerators, and the degree of comfort respondents feel with the questioning, research schedule and time taken in administering instruments. The challenges are compounded within the Young Lives study by the number of interactions with respondents over the life of the study and by the length of the instruments. Therefore, considerable effort is made to keep length of visits and instruments to a minimum, for example by focusing only on topics that are of direct relevance to child poverty.

Respecting respondents' schedules and building relationships of trust over time are essential. To this end, Young Lives has tried to ensure, as far as possible, that the field supervisors remain with the study across all survey rounds, and considerable effort also goes into selection and training of research teams. ${ }^{11}$ Training includes sessions on ethics and fieldwork manuals contain detailed ethics guidance (Morrow, 2009). The teams are at each site for several weeks, allowing them time to identify any potential obstacles to engagement with respondents. Effort is made to keep records of respondents' views about their involvement in the study and data-gathering reports provide information on ethical dilemmas that have arisen during fieldwork, ensuring that respondents' reflections on the research are used to improve interactions in subsequent rounds (Morrow, 2009). Any problems that do occur during fieldwork are reported to study-country principal investigators, who take appropriate remedial action in consultation with other team members.

Informed consent presents particular challenges in a cohort study insofar as it needs to be reconfirmed at each data round, and in researching children should include consent from caregivers, and in schools from principals and teachers, as well as child respondents once they are old enough (Morrow, 2009). In some contexts it can be

\footnotetext{
${ }^{11}$ See Penny and Madrid (2012) for an account of Young Lives approach to the selection and induction of supervisors for fieldwork in Peru.
} 
difficult to ensure that the highest ethical standards are maintained at all times. For example, it is hard to guarantee that children do not feel obliged to participate in research, simply because they would normally be expected to conform with the wishes of their elders. Strict confidentiality for children can be problematical in settings where the young do not generally have any privacy or seldom spend time in the company of adults outside the family. Researching children's experiences of poverty can involve sensitive lines of enquiry, as when asking poor children about their relationships with classmates and peers. In Young Lives, care is taken to ensure that questions are phrased in a way that minimises embarrassment or distress and children are reminded throughout that interviews can be terminated at any stage if they so wish.

Study participants are compensated for their time; a principle that is especially important given that many Young Lives households are quite poor and involvement in the research can disrupt their livelihoods. At the same time, reciprocal actions that involve reporting research findings back to households, communities and local officials enable respondents and others to learn about study findings and facilitate good long-term relations. While this is good practice in terms of respect for respondents, it presents a risk of data 'contamination', which is a particular concern in longitudinal research. Young Lives has accepted that it is almost inevitable that the research will have some influence on respondents' attitudes or lives, even if only insofar as asking questions about topics like school grades or vaccinations raises awareness of the relevance of these matters for children.

\section{Linking school surveys to a household survey design}

The introduction of nested school surveys has brought to the fore additional challenges and considerations related to the balancing of concerns for cohort and panel data maintenance with the generation of data that enable examination of policy-relevant questions of a more cross-sectional nature. At the initial design stage of the school surveys, the most attractive option involved following the younger cohort of children to their schools and classes, the aim being to add school-level data to the existing panel and to describe the schooling experiences of Young Lives children. This approach was taken in Ethiopia (2010) and India (2010-11) and has been exploited in diverse research outputs (see for example Frost and Little, this issue for Ethiopia; and Singh, forthcoming 2013 for India). However, as a result of the dispersion of Young Lives children across schools and classes, this approach produced a mixed number of children per class and school. Whilst yielding valuable policy-relevant research findings, both cross-sectionally and linked to the household panel, data from these surveys sometimes presented challenges for those research questions which required a more consistent number of children per class and school.

As such, an alternative 'hybrid' design evolved which included a sample of non-Young Lives children at the class and school level, This design achieves a more balanced sample at the school and class level and enables cross-sectional research focussed on the specific school, class and teacher-level factors that may ameliorate the 
disadvantages associated with household poverty. This hybrid design was employed in Peru (2011) Vietnam (2011-12) and Ethiopia (2012-13) to enable both the extension of the Young Lives child-level panel and the generation of a data set which robustly addresses questions of school effectiveness (see for example Krutikova et al, forthcoming 2013; Rolleston et al2013b). In Vietnam and Ethiopia school value-added analysis has also been possible.

The sub-sample of younger-cohort children in the school surveys was selected most commonly on the grounds of the grade and school in which they were studying. Since Young Lives children are distributed across a variety of school and non-school settings and school grades, translating an age cohort into a meaningful school cohort is challenging. Further, logistical constraints limit the number of schools it is possible to survey, and thereby restrict the sampling criteria. For example, the younger cohort children in India are scattered across more than 900 schools, such that a school sample which simply tracks a random sample of the children to their schools would risk producing a logistically impractical sample of schools. By contrast, in Vietnam, nearly two-thirds of the Younger Cohort sample (all of whom study in the same grade) can be reached by visiting just a little over fifty schools.

The second 'hybrid' approach to school survey sampling has limitations. Perhaps most crucial of these is that in including only those children studying at approximately the correct age-for-grade, we have excluded late enrollers, grade repeaters and those who enrolled in school early, or progressed quickly. This has the potential to introduce systematic bias into the sample of the Young Lives children for whom data are collected at the school level and it is important that comparisons of the main cohort and school samples highlight these differences (see Rolleston et al, 2013b) for a discussion in relation to Vietnam).

\section{Balancing comparability and relevance}

Another challenge in a multi-level, cross-country, mixed-methods, two-cohort, panel study is to ensure that the core research instruments are suitable for administration with diverse age, linguistic and cultural groups, conceptually and analytically coherent across the qualitative and quantitative components and at the same time retain the longitudinal design. The aim is to guarantee a degree of comparability in design and coverage of key survey themes and modules between countries (insofar as this is meaningful) and, perhaps more importantly, over time (the latter involving comparability in data rounds between cohorts and across the life of individual children). This needs to be achieved without compromising intelligibility and relevance in each country context and at each point in time, such that the data are suitable for cross-sectional and longitudinal enquiry and relationships and pathways identified within each country can, where meaningful, be compared across contexts. There are many competing demands involved in securing the integrity of the panel in a research design as complex as this and compromises have sometimes been inevitable, as 
between maintaining a core of questions across the full sample (both for ease and for coherence of survey coverage) and respecting the specific information requirements at the study-country level. In the case of education research, these compromises relate to the developmental and contextual appropriateness of instruments and measures as well as to curriculum and language of instruction issues.

Ensuring survey instruments are developmentally appropriate has meant shifting from adult respondents reporting about their children when the children were very young, to child respondents as the sample matures, and the reformulation of the child questionnaires and measures at each round. For the younger cohort this has involved devising questions in such a way as to be relevant and understandable to children in middle childhood. Achieving the Young Lives goal of including children's perspectives within the core survey design has not always been straightforward. Concepts of wellbeing, poverty, and risk are not easily translated into local languages at a level of concreteness suited to young children (Morrow and Boyden 2013). Developmental appropriateness entails effective communication with different age groups and selecting topics that can be adapted for age.

A balance is sought at each round between maintaining the integrity of the panel and revising the content to reflect children's age and stage of development. For example, older cohort questionnaires administered in the household surveys have evolved from a focus on education, well-being and related themes, to matters concerning the transition to adulthood, such as employment and earnings, marital and living arrangements and fertility. In this sense, one of the advantages of having two age cohorts is that questions that have been found to work well with the older group can be administered subsequently with the younger ones. Similarly, questions asked of caregivers can be used with the older cohort as they enter adulthood and live apart from their natal households. Thus, questions obtained from caregivers in Round one of the household survey about the feeding and weaning practices they employed with the younger cohort when they were infants are being applied at Round four to those young people in the older cohort who are now parents themselves, enhancing intergenerational analysis.

Data quality relies heavily on the inclusion and administration of context-appropriate questions and measures. Since surveys of this kind necessarily reduce social and cultural phenomena to simple indicators, with attendant loss of contextual information, local meanings and detail, it is important that additional bias is not introduced through the administration of context-inappropriate indicator questions. The significance of this is particularly clear in the selection and design of measures of learning, cognition and psychosocial competencies in both the household and school surveys. There has been a need to balance relevance of the research to the wider literature and debates - which has usually meant drawing on measures that are recognised internationally but which have seldom been validated in developing country contexts - with suitability for administration with children of varying ages and sometimes limited literacy who 
are growing up in diverse socio-cultural contexts. With this in mind, measures of learning in the school surveys have taken into account curriculum and learning expectations at the national level.

As noted, measures of learning and cognition in the household surveys are administered across some twelve language groups. Domains of importance across all study countries have been identified and attempts made to equate test items across linguistic groups, both within and between countries, as well as over time, to generate measures that are valid in diverse contexts. Psychosocial concepts such as 'self-efficacy' or 'self-concept' are highly contextual, and adaptation of established psychometric scales from one culture do not necessarily readily translate into meaningful measures of the same latent construct across cultures. Considerable effort has therefore been expended in piloting, translation and back translation of instruments and measures across the languages used in the study (see for example Cueto et al, 2009: Cueto \& Leon, 2012).

\section{Section 4: Conclusion}

Young Lives is an ambitious and distinctive study in a number of respects, insofar as it involves four diverse and rapidly changing developing countries, two cohorts of children, and the collection of both quantitative and qualitative data at the child household, community and school levels. The resulting analyses enable the identification of the changing influences and causal pathways which shape the lives of children and young people growing-up in contexts of poverty across four low and middle-income countries, with potentially important insights for policy and practice.

Inevitably, this design involves certain compromises. Attention to multidimensionality in the conceptualisation of both poverty and child development comes at the cost of depth in any single dimension of the research. The practicalities and expense of generating and maintaining a valid national child-level sample in varied geographical and political contexts are complex and sometimes prohibitive. The maintenance of a degree of comparability in design, and survey content, across countries, between cohorts and over time must be balanced with due consideration for relevance and appropriateness in relation to the diverse socio-cultural and linguistic settings which exist both within and between study countries. These challenges will no doubt continue to evolve as the study progresses and matures.

However, as the focus of educationalists internationally shifts increasingly toward the creation of universal learning metrics, and as calls for the use of experimental methods in education research increase, Young Lives experience reaffirms the importance of attention to relevance and context, including long-term engagement with stakeholders and policy-makers in country. Further, the insights offered by the longitudinal design underline the value of understanding the dynamic processes and institutions including education - which shape the lives of children and young people growing up 
in poverty contexts. Ultimately, this distinctive combination has the potential to serve as a key resource for meaningful systems reform across the world.

\section{$\underline{\text { References }}$}

Alderman, H., Behrman, J.R., Kohler, H.P., Maluccio, J.A., \& Watkins, S.C. (2000). Attrition in Longitudinal Household Survey Data: Some Tests for Three DevelopingCountry Samples. FCND Discussion Paper No. 96. Washington D.C., IFPRI.

Barnett, I., Ariana, P., Petrou, S., Penny, M., Le Thuc Duc, Galab, S., Woldehanna, T., Escobal, J., Plugge, E., \& Boyden, J. (2012). Cohort Profile: The Young Lives Study. Int. J. Epidemiology. First published online: May 21, 2012.

Brookings. (2011). A Global Compact on Learning: Taking Action on Education in Developing Countries, Washington, D.C., Centre for Universal Education at Brookings.

Bynner, J. (2005). Longitudinal cohort designs. in Kempf-Leonard, K (ed). Encyclopaedia of Social Measurement. San Diego, CA, Elsevier.

Bynner, J. \& Joshi, H. (2007). Building the Evidence Base from Longitudinal Data. Innovation: The European Journal of Social Science Research, 20:2, 159-179.

Crivello, G., Morrow, V., \& Wilson, E. (2013). Young Lives Longitudinal Qualitative Research: A Guide for Researchers, Young Lives Technical Note 26. Oxford, UK, Young Lives.

Cueto, S., \& Leon, J. (2012). Psychometric Characteristics of Cognitive Development and Achievement Instruments in Round 3 of Young Lives. Young Lives Technical Note 25, Oxford UK, Young Lives.

Cueto, S., Leon, J., Guerrero, G \& Munox, I. (2009). Psychometric characteristics of cognitive development and achievement instruments in Round 2 of Young Lives. Young Lives Technical Note 15, Oxford, UK, Young Lives.

Dercon, S. \& Singh, A. (2013). From Nutrition to Aspirations and Self-Efficacy: Gender Bias over Time Among Children in Four Countries, World Development 45:31-50.

Dearden, K., Crookston, B., Madanat, H., West, J., Penny, M., \& Cueto, S. (2013). What Difference Can Fathers Make? Early Paternal Absence Compromises Peruvian Children's Growth. Maternal and Child Nutrition 9(1): 143-54.

DFID. (2010). Learning for All: DFID's Education Strategy 2010-2015. London, DFID.

Escobal, J \& Flores, E. (2008). An Assessment of the Young Lives Sampling Approach in Peru. Young Lives Technical Note No. 3, Oxford, UK, Young Lives.

Frost, M \& Little, A. (forthcoming, 2014). Children's Learning Practices: observations from Ethiopian primary school classes. Oxford Review of Education 
Glewwe, P., Hanushek, E.A., Humpage, S.D. \& Ravina, R. (2011). School Resources and Educational Outcomes in Developing Countries: A Review of the Literature from 1990 to 2010. NBER Working Paper No. 17554, Cambridge MA, NBER.

Hill, Z. (2004). Reducing attrition in panel studies in developing countries. International Journal of Epidemiology, 2004: 33: 493-498.

James, Z. \& Woodhead, M. (forthcoming, 2014) Choosing and changing schools in India's private and government sectors: Young Lives evidence from Andhra Pradesh. Oxford Review of Education

Krutikova, S., Rolleston, C. \& Aurino, E. (forthcoming, 2013). Does School Make a Difference and for Whom? A two-country study of the impact of school quality on educational attainment.

Kumra, N. (2008). An Assessment of the Young Lives Sampling Approach in Andhra Pradesh, India. Young Lives Technical Note No. 2, Oxford, UK, Young Lives.

Morrow, V. (2009). The Ethics of Social Research with Children and Families in Young Lives: Practical Experiences. Working Paper No. 53, Oxford: UK, Young Lives.

Morrow, V. and Boyden, J. (2013) The Ethics of Researching Children's Well-Being. In A. Ben-Arieh, I. Frones, F. Casas, J. Korbin (eds.), Handbook of Child Well-Being, Springer Science and Business Media Dordrecht

Murray, H. (2012). Is School Education Breaking the Cycle of Poverty for Children?: Factors Shaping Education Inequalities in Ethiopia, India, Peru and Vietnam. Young Lives Policy Paper 6. Oxford, UK, Young Lives.

Nguyen, N.P. (2008). An Assessment of the Young Lives Sampling Approach in Vietnam. Young Lives Technical Note No. 4, Oxford, UK: Young Lives.

Outes-Leon, I. \& Dercon, S. (2008). Survey Attrition and Attrition Bias in Young Lives. Young Lives Technical Note 5, Oxford, UK, Young Lives.

Outes-Leon, I. \& Sanchez, A. (2008). An Assessment of the Young Lives Sampling Approach in Ethiopia. Young Lives Technical Note No. 1, Oxford, UK, Young Lives.

Outes-Leon, I \& Porter, C. (2013). Catching Up from Early Nutritional Deficits? Evidence from Rural Ethiopia, Economics and Human Biology 11(2): 148-63.

Penny, M., Ore, B. \& Madrid, S. (2012). Selection and Induction of Supervisors for Fieldwork. Young Lives Technical Note 24, Oxford, UK, Young Lives.

Porter, C., Sanchez, A. \& Nair, M. (2012). Surveying Siblings: The case for tracking brothers and sisters of Young Lives Index Children in Round 4 and Beyond. Young Lives Technical Note No. 23, Oxford, UK, Young Lives.

Rolleston, C., James, Z. \& Aurino, E 2013a. Exploring the effect of educational opportunity and inequality on learning outcomes in Ethiopia, Peru, India and Vietnam. Background paper prepared for the Education for All Global Monitoring Report 2013. Paris, France; UNESCO. 
Rolleston, C., James, Z., Pasquier-Doumer, L., Tran Ngo Thi Minh Tam, \& Le Thuc Duc. 2013b. Making Progress: Report of the Young Lives School Survey in Vietnam. Oxford, UK: Young Lives

Save the Children (2003). Child Protection Policy, London, International Save the Children Alliance.

Singh, A (forthcoming, 2013) Size and sources of the Private School Premium in test scores in India, Young Lives Working Paper

Wilson, I., Huttly, S.R.A., \& Fenn, B. (2006). A Case Study of Sample Design for Longitudinal Research: Young Lives. International Journal of Social Research Methodology, Vol. 9, No. 5, December 2006. pp. 351-365.

Woodhead, M., Murray, H., and Dornan, P. (2013a). What inequality means for children. Evidence from Young Lives. Oxford, UK, Young Lives.

Woodhead, M., Frost M. and James Z. 2013b. Does Growth in Private Schooling Contribute to Education For All? Evidence from a Longitudinal, Two-cohort Study in Andhra Pradesh, India, International Journal of Educational Development 33(1): 6573 
Figure 1: Overview of the core Young Lives sampling approach

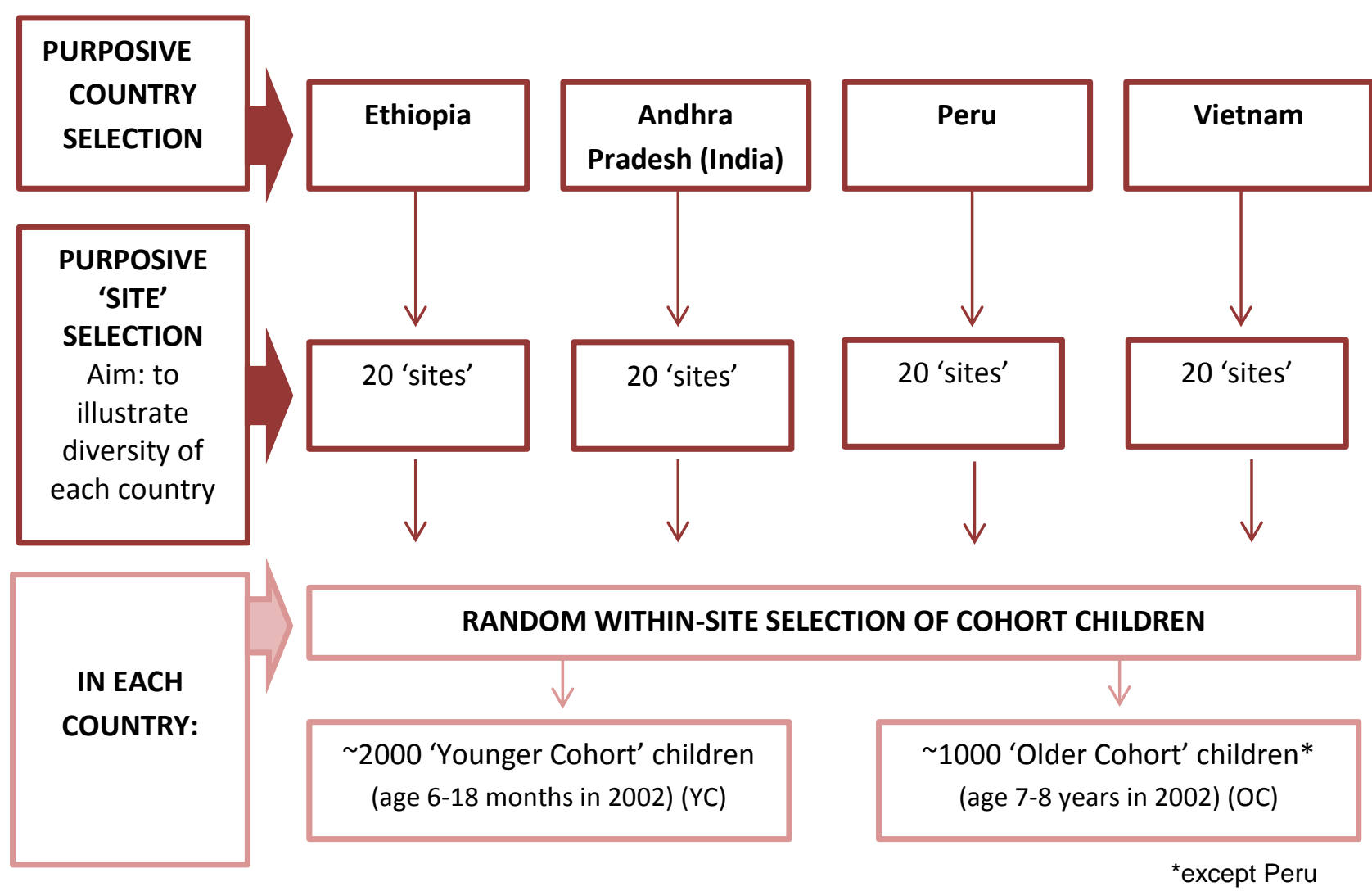


Table 1: Overview of the Young Lives survey design as at August 2013

\begin{tabular}{|c|c|c|c|c|c|c|c|c|c|}
\hline \multirow[t]{3}{*}{ Year } & \multirow[t]{3}{*}{ Survey round } & \multicolumn{8}{|c|}{ Number of Young Lives children } \\
\hline & & \multicolumn{2}{|c|}{ Ethiopia } & \multicolumn{2}{|c|}{ India (AP) } & \multicolumn{2}{|l|}{ Peru } & \multicolumn{2}{|c|}{ Vietnam } \\
\hline & & YC & OC & YC & OC & YC & OC & YC & OC \\
\hline 2002 & Household 1 & 1999 & 1000 & 2014 & 1014 & 2052 & 714 & 2000 & 1000 \\
\hline 2003 & \multirow{3}{*}{\multicolumn{9}{|c|}{-}} \\
\hline 2004 & & & & & & & & & \\
\hline 2005 & & & & & & & & & \\
\hline 2006 & \begin{tabular}{|l|l}
$\begin{array}{l}\text { Household } 2 \\
(2006-07)\end{array}$ \\
\end{tabular} & 1912 & 980 & 1950 & 994 & 1963 & 685 & 1970 & 990 \\
\hline 2007 & Qualitative 1 & $\sim 25^{*}$ & $\sim 25$ & $\sim 25$ & $\sim 25$ & $\sim 25$ & $\sim 25$ & $\sim 25$ & $\sim 25$ \\
\hline 2008 & Qualitative 2 & $\sim 25$ & $\sim 25$ & $\sim 25$ & $\sim 25$ & $\sim 25$ & $\sim 25$ & $\sim 25$ & $\sim 25$ \\
\hline 2009 & Household 3 & 1883 & 973 & 1932 & 976 & 1943 & 678 & 1954 & 971 \\
\hline \multirow[t]{3}{*}{2010} & $\begin{array}{l}\text { Ethiopia school } \\
\text { survey } 1\end{array}$ & 1120 & 770 & - & - & - & - & & - \\
\hline & \begin{tabular}{|l|} 
India school \\
survey 1 \\
$(2010-11)$ \\
\end{tabular} & - & - & 950 & - & - & - & - & - \\
\hline & \begin{tabular}{|l|}
$\begin{array}{l}\text { Qualitative } 3 \\
\text { (India) }\end{array}$ \\
\end{tabular} & - & - & $\sim 25$ & $\sim 25$ & - & - & & - \\
\hline \multirow[t]{3}{*}{2011} & $\begin{array}{l}\text { Vietnam school } \\
\text { survey } 1^{*} \\
(2011-12) \\
\end{array}$ & - & - & - & - & - & - & 1138 & - \\
\hline & $\begin{array}{l}\begin{array}{l}\text { Peru school } \\
\text { survey } 1^{*}\end{array} \\
\end{array}$ & - & - & - & - & 572 & - & - & - \\
\hline & $\begin{array}{l}\text { Qualitative } 3 \\
\text { (other } \\
\text { countries) }\end{array}$ & $\sim 25$ & $\sim 25$ & - & - & $\sim 25$ & $\sim 25$ & $\sim 25$ & $\sim 25$ \\
\hline 2012 & $\begin{array}{l}\text { Ethiopia school } \\
\text { survey } 2^{*} \\
(2012-13) \\
\end{array}$ & $\sim 500^{\star \star \star}$ & - & - & - & - & - & - & - \\
\hline 2013 & Household 4 & & & & & & & & \\
\hline 2014 & Qualitative 4 & & & & & & & & \\
\hline
\end{tabular}




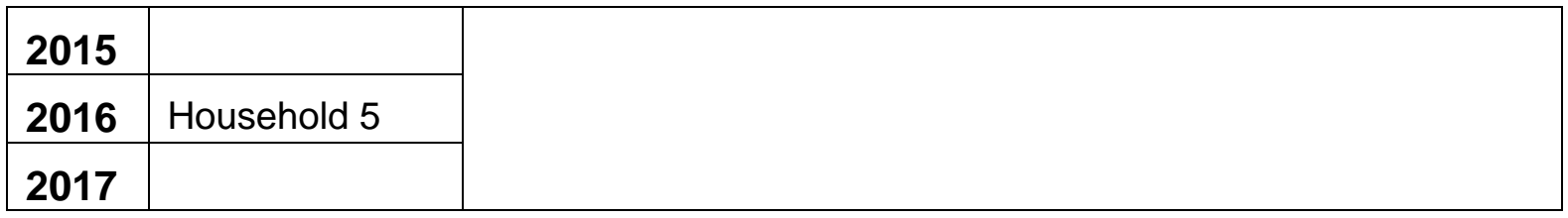

* The qualitative data collection includes approximately 25 children in each cohort in each round. This figure may vary slightly as not all the 'core' case study children may be available to participate in all the data collection exercises (such as group discussions) and/or throughout all of the rounds

**These surveys also included extended samples of non-Young Lives children at the class and school level

${ }^{* * *}$ At the time of writing this survey was still in process.

Table 2: Overview of school surveys, 2013

\begin{tabular}{|c|c|c|c|c|c|}
\hline \multirow{3}{*}{$\begin{array}{l}\text { School } \\
\text { survey }\end{array}$} & \multirow[t]{3}{*}{ Sampling notes } & \multirow{3}{*}{$\begin{array}{l}\text { One wave } \\
\text { or two? }\end{array}$} & \multicolumn{3}{|c|}{ Number of children } \\
\hline & & & \multicolumn{2}{|c|}{ Young Lives } & \multirow{2}{*}{$\begin{array}{l}\text { Non- } \\
\text { Young } \\
\text { Lives }\end{array}$} \\
\hline & & & OC & YC & \\
\hline $\begin{array}{l}\text { Ethiopi } \\
\text { a } \\
2010\end{array}$ & $\begin{array}{l}\text { Multi-stage. } \\
\text { selection of YL children and } \\
\text { schools, and addition of } \\
\text { other YL children in school }\end{array}$ & One wave & 770 & 1120 & 要要 \\
\hline $\begin{array}{l}\text { India } \\
2010\end{array}$ & $\begin{array}{l}\text { Stratified by school type \& } \\
\text { location. }\end{array}$ & One wave & - & 950 & - \\
\hline $\begin{array}{l}\text { Peru } \\
2011\end{array}$ & See Guerrero et al (2012) & One wave & - & 572 & 1207 \\
\hline $\begin{array}{l}\text { Vietna } \\
\text { m } \\
2011-12\end{array}$ & $\begin{array}{l}\text { All grade } 5 \text { classes attended } \\
\text { by a YL child in schools } \\
\text { within the sentinel site }\end{array}$ & Two waves & - & 1138 & 2146 \\
\hline $\begin{array}{l}\text { Ethiopi } \\
\text { a } \\
\text { 2012-13 }\end{array}$ & $\begin{array}{l}\text { All pupils in all grade } 4 \text { and } 5 \\
\text { classes in schools within the } \\
\text { sentinel site }\end{array}$ & Two waves & - & $\sim 500$ & $\sim 11,500$ \\
\hline
\end{tabular}

Table 3: Attrition rate household survey rounds 1-3 (excluding deaths)

\begin{tabular}{|l|l|l|l|l|}
\hline Cohort & Country & $\begin{array}{l}\text { Attrition from } \\
\text { Round 1 } \\
(\%)\end{array}$ & $\begin{array}{l}\text { Attrition from } \\
\text { Round 2 } \\
(\%)\end{array}$ & $\begin{array}{l}\text { Attrition from } \\
\text { Round 1 to 3 } \\
(\%)\end{array}$ \\
\hline \multirow{3}{*}{$\begin{array}{l}\text { Older } \\
\text { Cohort }\end{array}$} & Vietnam & 0.9 & 1.8 & 2.7 \\
\cline { 2 - 5 } & India & 1.8 & 1.5 & 3.3 \\
\cline { 2 - 5 } & Peru & 3.7 & 0.7 & 4.4 \\
\cline { 2 - 5 } & Ethiopia & 1.4 & 0.7 & 2.1 \\
\cline { 2 - 5 } & Total & 1.8 & 1.2 & 3.0 \\
\hline \multirow{3}{*}{$\begin{array}{l}\text { Younger } \\
\text { Cohort }\end{array}$} & Vietnam & 1.0 & 0.8 & 1.8 \\
\cline { 2 - 5 } & India & 1.6 & 0.7 & 2.3 \\
\cline { 2 - 5 } & Peru & 3.5 & 0.9 & 4.4 \\
\cline { 2 - 5 } & Ethiopia & 1.3 & 0.9 & 2.2 \\
\cline { 2 - 5 } & Total & 1.9 & 0.8 & 2.7 \\
\hline
\end{tabular}


i Young Lives is core-funded by the UK Department for International Development (DFID) and the Netherlands Ministry of Foreign Affairs (DGIS) for the benefit of developing countries, with sub-studies funded by The Bernard van Leer Foundation, the International Development Research Centre (IDRC), the Oak Foundation and UNICEF. The study is managed by the University of Oxford and operates through partnerships with 13 institutions in the UK and study countries, this structure being crucial to the effective implementation of a multi-country, multi-site, mixed-methods cohort study. 